\title{
Research on Global Structure for Digital Quality Testing Based on Manufacturing Factory
}

\author{
Mengqing Tanli*, Yan Jiang, Xiang Wang, Yulin Wang and Rushu Peng \\ School of Mech. \& Eng., University of South China, Hunan, Hengyang, China, 421001 \\ * Corresponding author
}

\begin{abstract}
This paper discusses the global structure of the digital quality testing, and briefly investigates the arrangement of testing equipment and hardware, the composition of software, the responsible branch and personnel, the control structure of quality data and information, and the arrangement of measuring method in digital quality testing. This global structure can give a unified model for research and application of digital quality testing.
\end{abstract}

Keywords-global structure; digital quality testing; manufacturing factory; control structure

\section{INTRODUCTION}

Advanced measuring and testing technology have got great achievement after producing and developing of computer and information technology, and there are four trends: (a) automation, integration and digitalization, (b) improving the performance and accuracy of measuring and testing, (c) on-line and in-process inspection, and (d) dynamically measuring and multi-parameters testing[1-4]. Digital quality testing embodies the trend and guide post of quality testing and quality control. Main advantages of digital quality testing are: (a) eliminating the error of index, and improving the accuracy of indexing, (b) accelerating the speed of response for inspection, (c) fitted to transferring for far instance and decreasing the mistake of manual, (d) being benefited to successive dispose of computer , and (e) improving safety of instrument and briefness of fabrication and maintenance.

Aspects of digital quality testing are: (a) digitalization of quality information acquisition and gathering, (b) displaying of digital quality information, (c) communication of digital quality information, and (d) quality information processing in digital computer[5-7].
Digital quality testing will continuously develop by application, in which, the shop floor will be a main aspect especially for manufacturing enterprise. Workers in factory incoming testing are very laboriou especially night and open working, and digital tester and instrument can be applied to improve effieciency and decrease the strength of labor. Application of digital quality testing can improve the assurance of accuracy and authority of measuring and testing in process testing. And consistency and effectiveness can also be lifted for finish product testing with the usage of digitalization technology[6-7].

Advanced testing technology is taken effect by digital testing, and digital quality testing will execute by a lot of digital testing units with digitalization technology, and this kind of execution is supported by all kind of composed elements to implement functional integration of quality testing, the illustration is showed in figure $1[2]$.

\section{Overall Structure of Digital Quality Testing}

The overall structure is a general view for digital quality testing. This view of digital quality testing is summarized according to operating procedure of quality testing in the actual manufacturing enterprise. The operating procedure of digital quality testing should be divided into four parts: factory incoming digital testing, digital testing of process quality, digital testing of finish quality, and assembly quality digital testing. Their main working are descript in the following.

\section{A. Factory Incoming Digital Testing}

Factory incoming testing mainly refers to standard part and raw material for manufacturing enterprise. The test type is mainly sampling test according to GB28.1, and its responsibility is usually belong to test department[7].

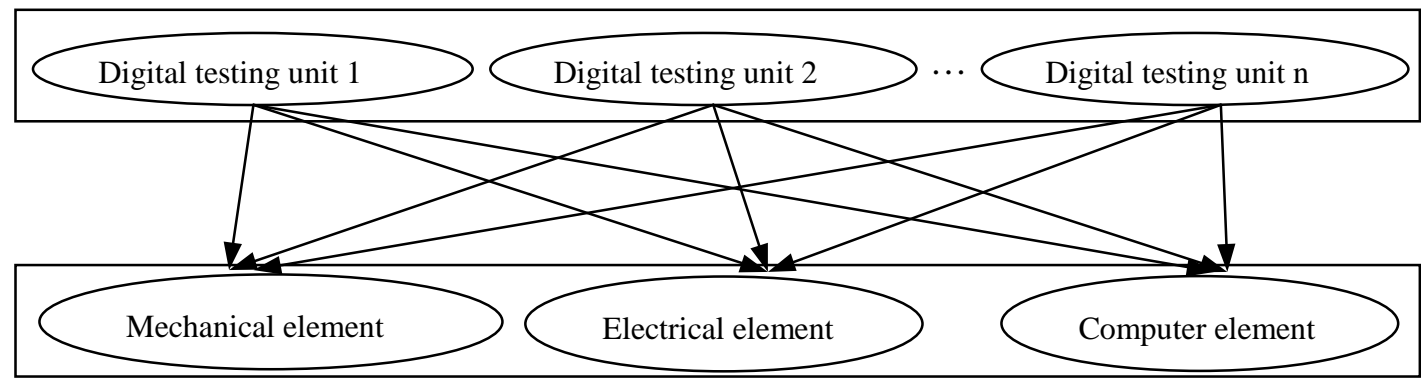

FIGURE I. LOGICAL RELATIONSHIP BTWEEN DIGITAL QUALITY TESTING UNIT AND ELEMENTS 


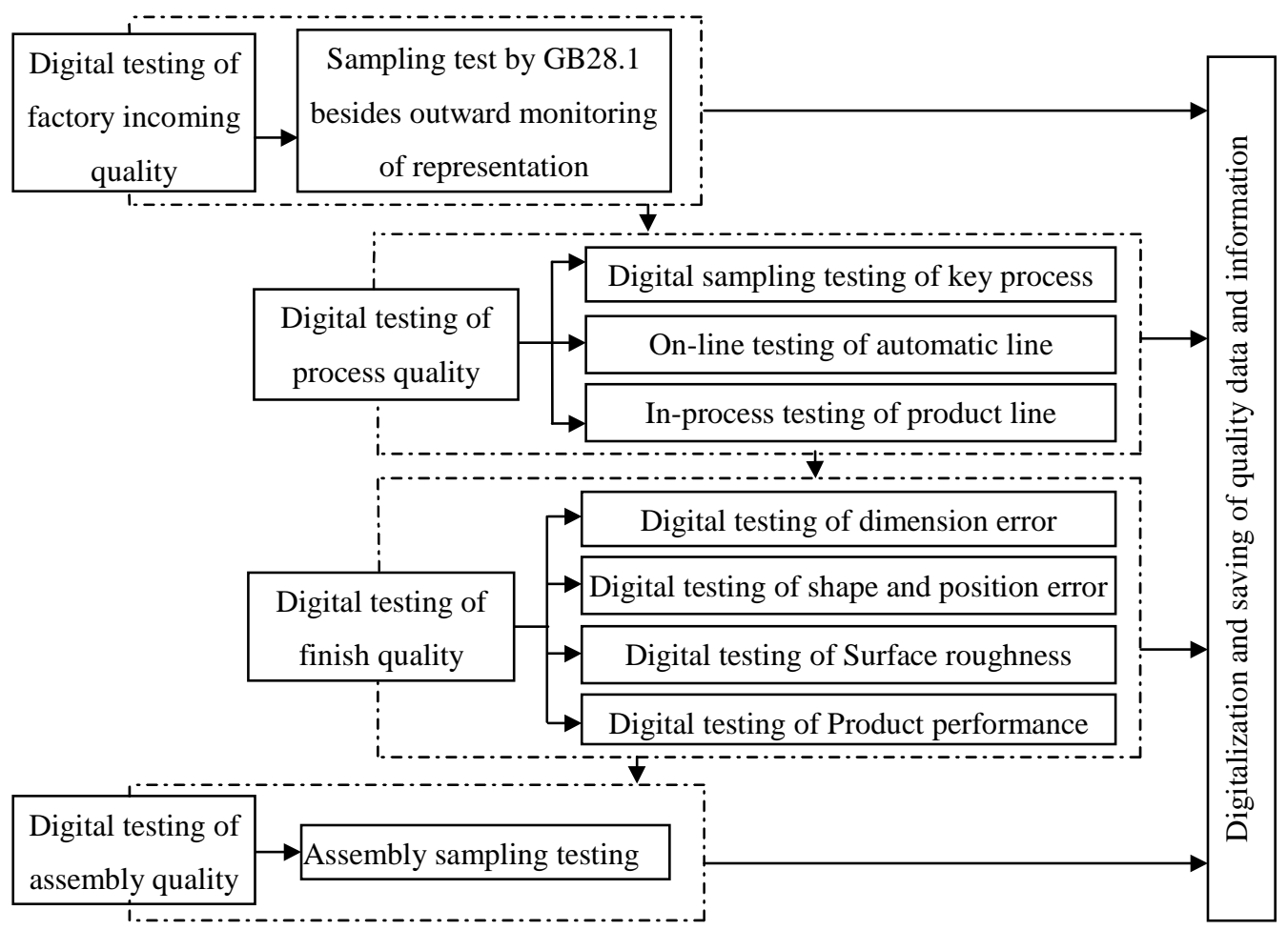

FIGURE II. OVERALL STRUCTURE OF DIGITAL QUALITY TESTING

\section{B. Digital Testing of Process Quality}

Process quality mainly refers to core and main machining part for manufacturing enterprise. There are various test types: in-process test and off-process test, on-line test and off-line test, manual test and automatic test. And its responsibility is usually belongs to workshop, besides special sampling test by test department[6].

\section{Digital Testing of Finish Quality}

Finish quality includes finish test of part and finish test of product, finish test of product usually belongs to assembly quality test for manufacturing enterprise. Similarly, various test types are used for finish test of part. And its responsibility is usually belongs to workshop and test department[6]

\section{Assembly Quality Digital Testing}

Assembly quality test is the final test, and advanced inprocess test and on-line test are gradually becoming the main type for manufacturing enterprise. Some manufacturing enterprise usually setup center of measuring and testing. As above, its responsibility is usually belongs to test department and workshop.

\section{DETAILED Divisions UNDER OVERALl STRUCTURE}

For digital quality testing with update advanced technology, the layout and arrangement is very important under the overall structure.

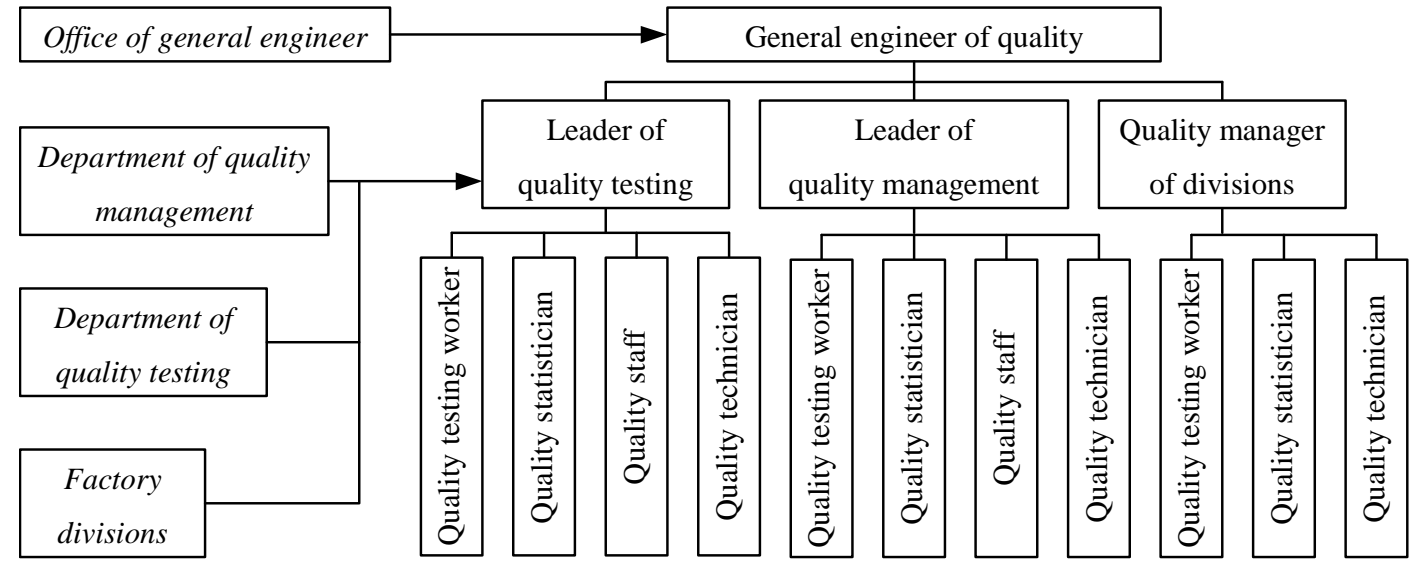

FIGURE III. RESPONSIBLE BRANCH AND PERSONNEL OF QUALITY TESTING 


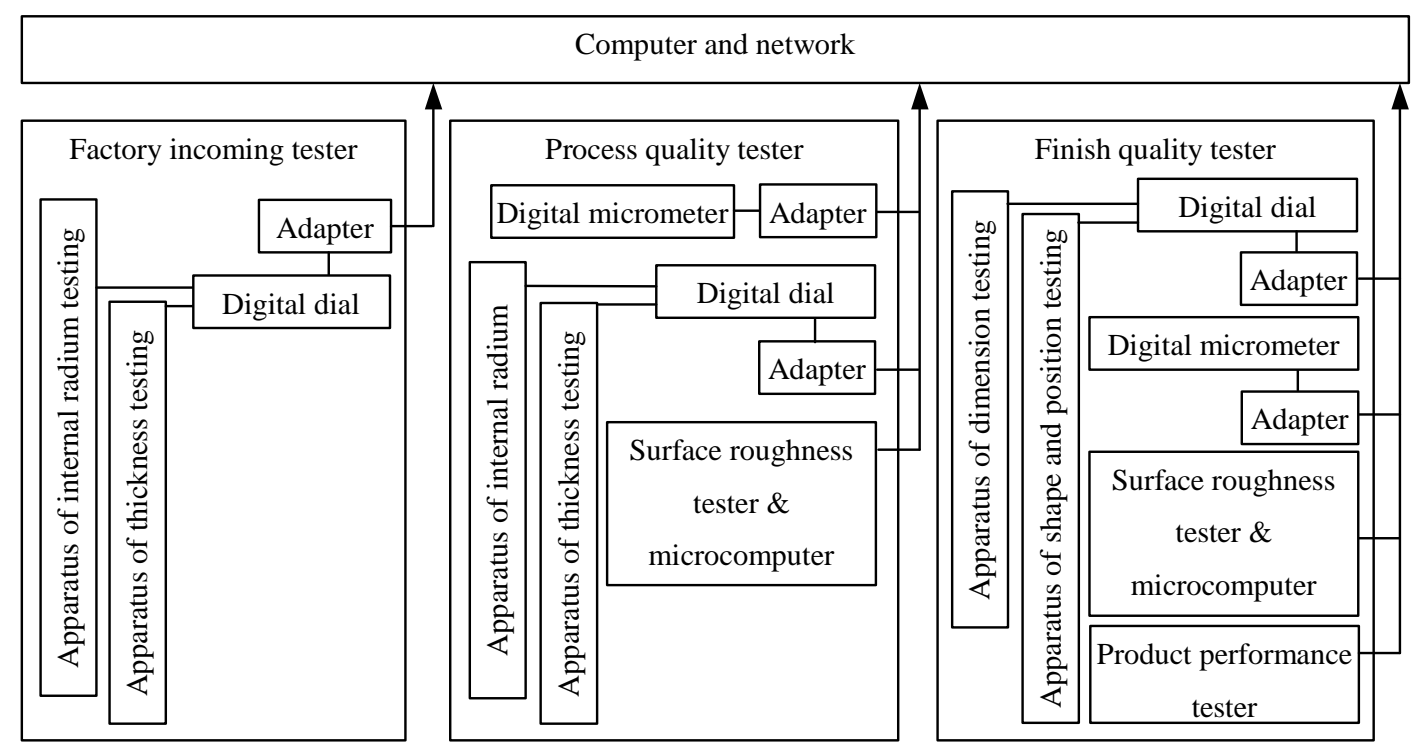

FIGURE IV. ARRANGEMENT OF TESTING EQUIPMENT AND HARDWARE

\section{A. The Responsible Branch and Personnel of Digital Quality Testing}

Digital quality testing must be executed by concrete department and personnel, quality testing work should respectively finished by their cooperation. The responsible branch and personnel of digital quality testing is shown in figure 3.

\section{B. The Arrangement of Testing Equipment and Hardware}

In digital testing, testing equipment and hardware is the primary base and carrier. With the development of electric and computer technology, testing equipment and hardware is becoming automatic, digital and integrated. In these testing equipment and hardware, apparatus and device are mainly belong to mechanics, and will become advanced inspection system by adding digital dial and meter or probe. As computer is applied, the performance and processing speed will be strengthen greatly, and construction of network among testing computers will achieve integration of quality testing data and information. The figure 4 has illustrated the arrangement of testing equipment and hardware according to quality testing type[6,8].

\section{The Composition of Software in Digital Quality Testing}

With the development of application of digital instrument and computer in quality testing, the usage of software is more and more. Especially, computer will be useless without support of software. Generally, software is divided into three parts: basic software, support software and professional application software, professional application software for digital quality testing includes: factory inspection program, quality testing program and quality monitoring program. Support software should include: usual usage, word processing software, and so on. Basic software should include: operation system, driving software, etc. Detail is shown in figure 5[9].

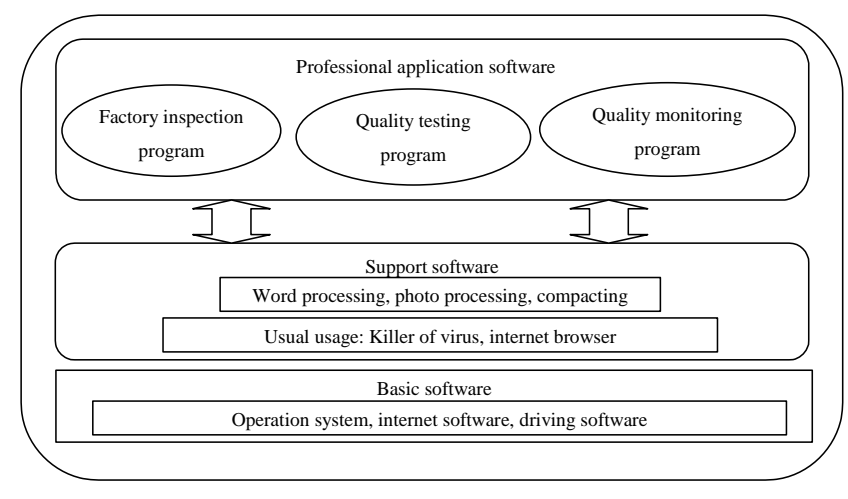

FIGURE V. COMPOSITION OF SOFTWARE

D. The Control Structure of Quality Data and Information

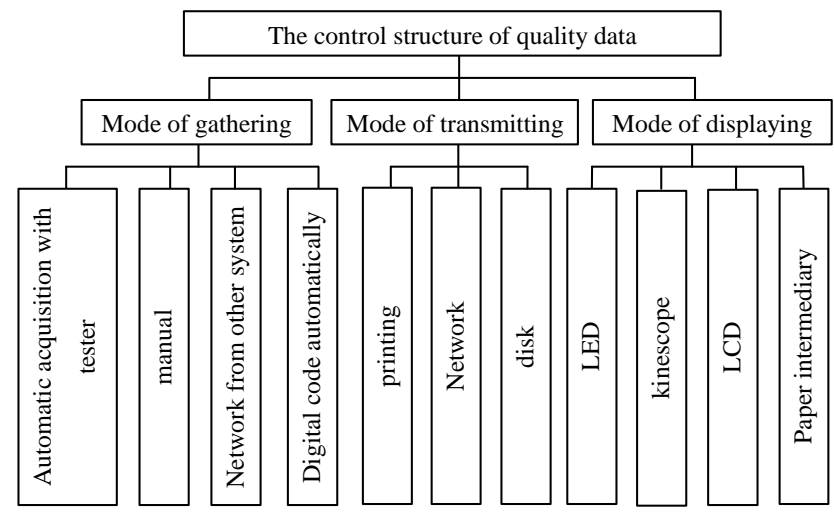

FIGURE VI. CONTROL STRUCTURE OF DATA

Aim of quality management is assurance of product quality, quality data is foundation and result of quality testing, and the control structure of quality data is very important. Generally according to the disposing flow of quality data, the control structure of quality data should include three aspects: (a) 
acquisition and gathering mode, (b) transmitting and media type, and (c) displaying and outputting way.

\section{E. The Arrangement of Measuring Method in Digital Quality Testing}

The measuring method in quality testing is usually divided according to three means, there are: (a) absolutely measuring and relatively measuring (comparatively measuring), (b) directly measuring and indirectly measuring, (c) measuring for single parameter and measuring for multi- parameters. Reasonable measuring method is benefited to improve inspecting accuracy and simplify the measuring mechanics. In manufacturing factory, main measuring and testing aspects include: (a) dimension measuring, (b) shape and position measuring, and (c) roughness measuring etc., and there are fitted measuring method respectively, detail is shown in figure 7.

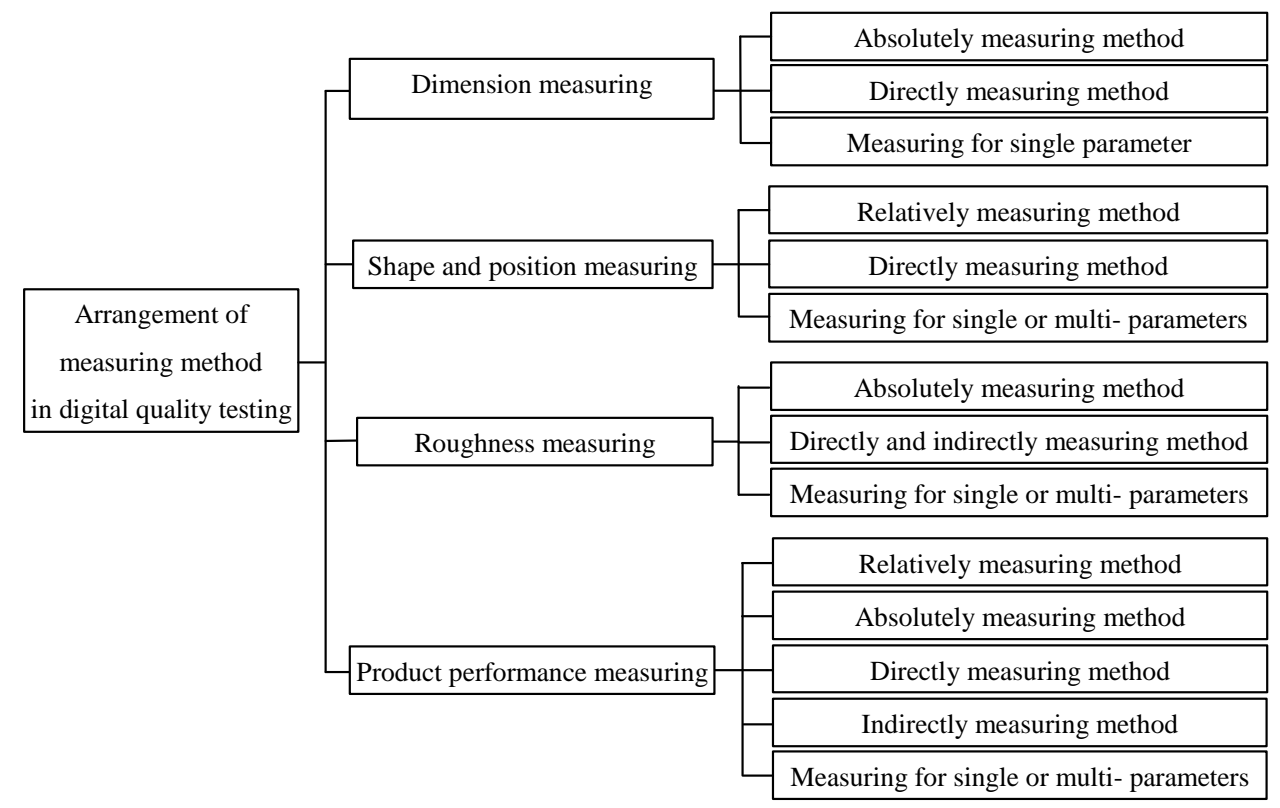

FIGURE VII. ARRANGEMENT OF MEASURING METHOD

\section{CONCLUSIONS}

Digital testing is the trend of quality testing, the execution of digital quality testing based on manufacturing factory may do step by step. The overall structure of digital quality testing may be unified according to operating procedure of quality testing in the actual manufacturing enterprise, generally including four parts: factory incoming quality testing, process quality testing, finish quality testing, and assembly quality testing. The responsible branch and personnel of digital quality testing should be organized according to actual factory, but the responsibility should be respective and clear. The implementation of layout of testing equipment and hardware should embody the development of advanced measuring and testing technology, at the same time, using and reuse of old equipment is very important. Software in digital quality testing should be designed and developed by self to meet the requirement of actual factory. The dispose of quality data and information should apply all kinds of types and backup is good mean to safety of quality data and information. Reasonable measuring method should be selected in digital quality testing to assure the standardization and generalization of testing equipment.

\section{REFERENCES}

[1] Zhang Gongxu, new quality management, high education press, May, 1998.(In chinese)
[2] Li Lin, Xue Chenqi, Review of the Research and Development of Computer Aided Kansei Engineering, IDDME \&ACCSPI2008, Beijing, Sept., 2008.

[3] Zhao Haibin, Nabil Anwer, Pierre Bourdet, Wang Junying, Multi-sensor Integration for Coordinate Metrology, IDDME \&ACCSPI2008, Beijing, Sept., 2008.

[4] TanLi Mengqing, Development and simulated test of WEBSPC, IDDME \&ACCSPI2008, Beijing, Sept., 2008.

[5] TanLi Mengqing, Distributed quality system under the condition of wireless network, $20142^{\text {nd }}$ International Conference on Teaching and Computational Science (ICTCS2014), July. 29-30, 2014,ShenZhen, China.

[6] TanLi Mengqing, Jiang Yan, Wang Xiang,et al., Research on Quality Tests for Shop Floor Application Based on Local Network, International Conference on Automatic Control and Information Engineering ICACIE2016, Oct. 22-23,2016, Hongkong, China.

[7] TanLi Mengqing, Jiang Yan, Wang Yulin,et al., Research on integration of quality testing based on communication technology, 2016 International Conference on Computer Networks and Communication Technology (CNCT2016), December. 16-18, 2016, China.

[8] GENG Hong qin, ZHANG Yuanying, Wireless Network and the Method of Building, Journal of Tianzhong, 2002, 5: 24-25.

[9] A.Kusiak, T.Letsche and A.Zakarian. "Data modeling with IDEF1x, International Journal of Computer Integrated Manufacturing”, 1997, 10 (6): pp470-487. 